\title{
Tionamide Agranulocytosis, A Complication Fearednot to Forget
}

\author{
Christian Pérez Calvo ${ }^{1 *}$, Carlos Daniel Orozco Sierra ${ }^{1}$ and Nehomar Pájaro-Galvis ${ }^{2}$ \\ ${ }^{1}$ Department of Internal Medicine, Free University of Barranquilla, Colombia \\ ${ }^{2}$ Department of Internal Medicine, Sinú University, Colombia \\ *Corresponding author: Christian Pérez Calvo, Department of Internal Medicine, Free University of Barranquilla, Colombia. \\ To Cite This Article: Christian Pérez Calvo, Carlos Daniel Orozco Sierra, Nehomar Pájaro-Galvis. Tionamide Agranulocytosis, A Complication \\ Fearednot to Forget. Am J Biomed Sci \& Res. 2021 - 14(3). AJBSR.MS.ID.001994. DOI: 10.34297/AJBSR.2021.14.001994.
}

Received: 紫 September 09, 2021; Published: 眥 October 06, 2021

\begin{abstract}
An unusual case of a 49-year-old female patient with a history of hyperthyroidism in management with mettimazole 40mg/day is presented. Quien is admitted to the ICU with a picture of febrile neutropenia secondary to agranulocytosis caused by the toxic effect of metymazole and the development of septic shock. When performing the assertive diagnosis, the drug was immediately discontinued and therapy with granulocytic colony growth factor was initiated, later the patient presents successful clinical improvement, is discharged from the ICU and continued its management in the general ward.
\end{abstract}

Keywords: Agranulocytosis; Hyperthyroidism; Febrile Neutropenia; Metamizole

\section{Introduction}

Hyperthyroidism is a relatively common condition that encompasses a spectrum of pathologies within which the most frequent is Grave's disease. The thyrotoxic effect of these diseases causes multiple alterations at the level of several systems. For the control of the same, there is a range of therapeutic options within which the tionamides top the list; among these we find metimazole, carbimazole (not available in Colombia) and propylthiouracil, the most used being the first [1]. Among the most frequent side reactions of metyazole are skin rash and pruritus in approximately $5 \%$ of patients [2,3], which do not represent severity and can be easily managed. However, there is a rare and serious adverse reaction, with potentially fatal complications whose pathophysiology is not clear, agranulocytosis, which is estimated to occur in 0.2 to $1 \%$ of patients [3] and whose real incidence in our country is unknown, based then on series from other countries which is estimated at $0.28 \%$ in the first 3 months of treatment [3], undoubtedly extremely low. Agranulocytosis can also be caused by other drugs, not being exclusive to metyazole, being more difficult to diagnose in some cases. Among the drugs that share this rare reaction are antibacterial agents such as trimetropin/sulfamethoxazole, some antipsychotics such as clozapine and risperidone, anticonvulsants such as carbamazepine and valproic acid, and nonsteroidal anti-inflammatory drugs (NSAIDs), all of which are widely used in medical practice [4,5]. This article presents the case of a 49-year-old patient with a history of hyperthyroidism, without other antecedents, in management with mettimazole for several months, who entered the ICU of our institution with a picture of febrile neutropenia secondary to agranulocytosis caused by the toxic effect of mettimazole and the development of septic shock, who in addition to the integral management of septic shock was managed with growth factors of granulocytic colonies responding appropriately. Next, a brief presentation of the case will be made and then the reflections that it raises, and a brief summary of the pathophysiology, diagnosis and management of the picture will be discussed according to what is found in the literature to finally establish the pertinent conclusions.

\section{Design}

Case Report. 


\section{Presentation of the Case}

We present the case of a 49-year-old female patient with a history of hyperthyroidism in management with mettimazole $40 \mathrm{mg}$ /day, who consults the emergency department with a picture of 3 days of evolution characterized by diarrheal episode with abundant stools of liquid consistency in number of 5 a day, fever, sensation of palpitations, dizziness, and syncopal episode, which is why she consults. Upon admission to the emergency department, the physical examination is evident in poor general condition, with signs of dehydration, tachycardia, without other alterations referred. You have a blood test performed upon admission to the institution: Wherethere is evidence ofa remarkable finding in the blood count, deep neutropenia, with an absolute count of 0.02 neutrophils $\times 10^{3} \mathrm{~mm}^{3}$, but in addition to this also the presence of leukopenia and anemia. It stands out in the other laboratory tests the presence of organic dysfunction, with alteration of renal function due to acute kidney injury, hepatic dysfunction with hyperbilirubinemia and prolongation of coagulation times and hydroelectrolyte imbalances due to hyponatremia, hypochloremia and moderate hypokalemia. Elevated acute phase reactants. EKG with sinus tachycardia. The patient evolves towards hypotension and hemodynamic instability requiring initiation of vasopressor support with noradrenaline and is referred to the ICU for the proper management of the case, considering herself to be present with a septic shock of gastrointestinal origin. Medical treatment is initiated for it including broad-spectrum antibiotic therapy. Once other diagnoses were excluded and with persistence of hematological alterations, it was evaluated by the hematology service of the institution considering the toxicity by thionamides and agranulocytosis as a toxic effect of methimazole. Once this diagnosis was made, the drug was immediately discontinued and therapy with Filgrastim granulocytic colony growth factor was initiated at doses of $300 \mathrm{mcg}$ s.c every 12 hours. The patient, when resolving the shock picture and presenting clinical improvement, is discharged from the ICU and continues her management in the general ward, evidencing improvement of the cell counts of leukocytes and neutrophils 24 hours after the start of the management and suspended the antithyroid, and her complete recovery at 8 days, even evidencing leukocytosis by great stimulation of bone marrow, suspending the Filgrastim and in subsequent blood count controls presenting a clear tendency to the normalization of cell lines. She was discharged from the hospital with beta-blocker management to control symptoms related to hyperthyroidism and an appointment with endocrinology to establish the proper management of her pathology.

\begin{tabular}{|l|c|}
\hline \multicolumn{2}{|c|}{ Table 1: Paraclinics Admission. } \\
\hline \multirow{4}{*}{$\begin{array}{c}\text { Blood count and } \\
\text { reticulocytes }\end{array}$} & White Blood Cells: 0.540 cell $/ \mathrm{mm}^{3}$ \\
\cline { 2 - 3 } & Lymphocytes \%: 51.9 monocytes \%: 42.6 \\
\cline { 2 - 3 } & Eosinophilis \%: 0.0 \\
\cline { 2 - 3 } & Neutrophilis: $3.6 \%$ \\
\cline { 2 - 3 } & Red G. Count 3.5 \\
\cline { 2 - 3 } & Hemoglobin $9.9 \mathrm{~g} / \mathrm{dl}$, Hemotocrit: $28.7 \% \mathrm{VAW}$ \\
\hline
\end{tabular}

Table 2: Blood Count and Reticulocytes.

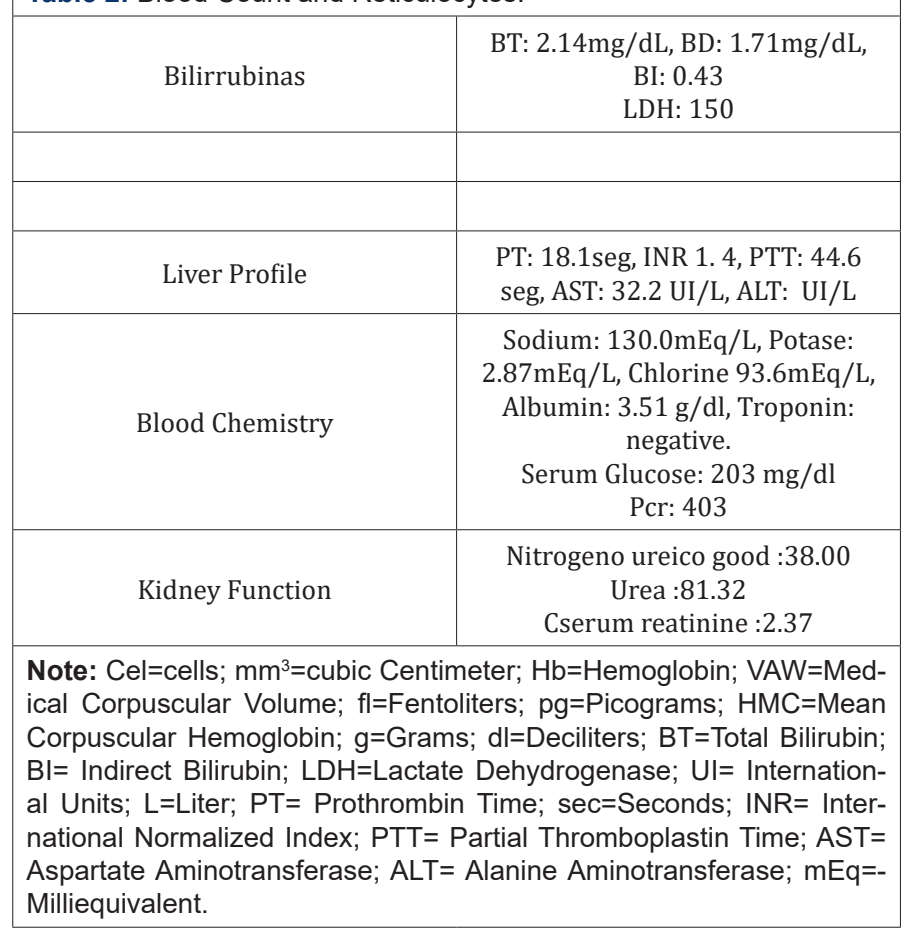

\section{Discussion}

Febrile neutropenia by antithyroid drugs is rare in Colombia and the mechanism by which it occurs is not clear enough; however, it is postulated that an autoimmune humoral reaction occurs against stem cells in the bone marrow. Genetic studies have also been conducted in which it has been determined that patients with Grave' s disease who carry the HLA DRB1*08032 allele may have susceptibility to produce metymazole agranulocytosis [6]. It has been documented that approximately $5 \%$ of patients may present with rash and pruritus [7]. In the city of Barranquilla (Colombia), there is a study as an antecedent, in which the safety of metymazole in the treatment of hyperthyroidism due to Grave's disease in children under 18 years of age was determined, in which 
$10 \%$ of the evaluated population presented mild leukopenia and responded adequately to the suspension or adjustment of the drug without other associated complications [8].

There is no conclusive evidence that drug-induced neutropenia could be dose dependent; most studies worldwide reveal that this event most often occurs in patients receiving doses equal to or greater than $30 \mathrm{mg} / \mathrm{d}$. Conversely, other studies have found that thionamide-induced neutropenia is independent of dose, age, duration of treatment, or second exposure to the drug [9] Patients with Grave's disease may occasionally course with neutropenia before initiating treatment wit h tionamides, due to the unpredictable and idiosyncratic nature; for this reason, most experts recommend monitoring the blood count [10] It is important to educate the patient about this complication, and is instructed to discontinue the drug, if he has fever and sore throat. The prognosis of drug-induced neutropenia has improved with advances in supportive therapy, including antibiotics, blood transfusions, and the use of granulocytic colony-stimulating factor (GM-CSF) [11].

\section{Conclusion}

There is no specific method to predict the occurrence of febrile neutropenia by mettimazole; its establishment can be abrupt, in many cases [12] Febrile neutropenia induced by tionamides is a diagnosis that must be discarded, early identification will allow timely interventions to be established, since in general although it has serious complications due to associated infectious processes, the recovery in the neutrophil count is relatively fast after the suspension of the drug in a timely manner, with this case report we want to highlight the importance of working together and reach anearlydiagnosis, since it has a high impact onmortality.

\section{References}

1. Cooper DS (2005) Antithyroid Drugs. N Engl J Med 13.

2. Serrano RYM, Cucunubá-Toloza A, Díaz-Hernández AT, EstradaRedondo C, Silva-Sanchez O (2019) Febrile neutropenia associated with metymazole intake: case report (916): 9.

3. Melmed S, Koenig R, Rosen C, Auchus R, Goldfine A (2019) Williams Textbook of Endocrinology. Elsevier pp. 364-403.

4. Goldman L, Ausiello DA, Schafer AI (2017) Goldman-Cecil Internal Medicine Treatise pp. 2625-2629

5. Lorenzo-Villalba N, Alonso-Ortiz MB, Maouche Y, Zulfiqar AA, Andrès E (2020) Idiosyncratic Drug-Induced Neutropenia and Agranulocytosis in Elderly Patients. J Clin Med. 10 de junio de 9(6):1808.

6. Watanabe N, Narimatsu H, Noh JY, Yamaguchi T, Kobayashi K, et al. (2012) Antithyroid Drug-Induced Hematopoietic Damage: A Retrospective Cohort Study of Agranulocytosis and Pancytopenia Involving 50,385 Patients with Grave's Disease. J Clin Endocrinol Metab. enero de 97(1): 49-53.

7. Franklyn JA (2009) Antithyroid therapy best choice of drug and dose. Nat Rev Endocrinol. noviembre de 5(11): 592-594.

8. Alvira J, Galván G, Ordóñez J, Parga C (2016) Efficacy and safety of metymazole in the treatment of hypothyroidism due to severe disease in children under 18 years of age. Barranquilla Biosciences 11(1): 41-47.

9. Tajiri J, Noguchi S (2005) Antithyroid Drug-Induced Agranulocytosis: How has Granulocyte Colony-Stimulating Factor Changed Therapy? Thyroid. marzo de 15(3): 292-297.

10. Mourot-Cottet R, Maloisel F, Séverac F, Keller O, Vogel T, et al. (2016) Idiosyncratic Drug-Induced Severe Neutropenia and Agranulocytosis in Elderly Patients ( $\geq 75$ years): A Monocentric Cohort Study of 61 Cases. Drugs-Real World Outcomes. diciembre de 3(4): 393-399.

11. Kim H, Lee J, Ha J (2018) A case of antithyroid drug-induced agranulocytosis from a second antithyroid drugs (ATD) administration in a relapsed Grave's disease patient who was tolerant to the first ATD treatment. Clin Case Rep. septiembre de 6(9): 1701-1703.

12. Johnston A, Uetrecht J (2015) Current understanding of the mechanisms of idiosyncratic drug-induced agranulocytosis. Expert Opin Drug Metab Toxicol. Febrero de 11(2): 243-257. 